\title{
Unusual Case of Pharyngeal Foreign Body: Metal Spoon in An Adult (Case Report)
}

\author{
Hicham Lyoubi*, Mouna Lyoubi, Kaoutar Chaker, Adil Lekhbal, Reda Allah Abada, Sami Rouadi, Mohammed \\ Roubal and Mohammed Mahtar
}

ENT and Head and Neck Surgery, Hospital August 20, Ibn Rochd Teaching Hospital, Casablanca-Morocco

*Corresponding author: Hicham Lyoubi, ENT and Head and Neck Surgery, Hospital

August 20, Ibn Rochd Teaching Hospital, Casablanca-Morocco.

\begin{abstract}
Foreign body ingestion is a common emergency. Adults we count $20 \%$ of the reported cases of foreign body aspiration. We describe an uncommon case of a young 27-year-old patient, who accidentally ingested a big metal spoon. The cervical X-ray shows the presence of a metallic foreign body at cervical and thoracic esophagus. The extraction of the foreign body under general was without notable incidents, and referred to a psychiatric consultation, according to the nature of the foreign body and the circumstances of occurrence.
\end{abstract}

Keywords: Pharyngeal foreign body; Unusual; Adult

\section{Introduction}

Foreign body ingestion is a common complaint in medical emergencies of otolaryngologist around the world. Ingestion of foreign body can occur among all age groups. Adults account for only about $20 \%$ of the reported cases of foreign body aspiration $[1,2]$. Metal spoons are common items in daily human life. However, to our knowledge there have been no cases of ingestion of these foreign bodies reported. Here, we report an uncommon case of a young 27-years-old patient, who accidentally ingested a big metal spoon.

\section{Case Presentation}

We describe the case of a young 27-year-old patient, with no medical history, who presents to the emergency room 4 hours after accidentally ingesting a metal spoon, with no notion of dyspnea but total dysphagia with hypersialorea. The examination of the oral cavity was without particularities.

The cervical X-ray shows the presence of a metallic foreign bodat cervical and thoracic esophagus (Figure 1). An exploration under

general anesthesia after 6 hours of fasting, allowed the extraction of the foreign body without notable incidents, the second look does not find lesions of the esophageal mucosa (Figure 2).

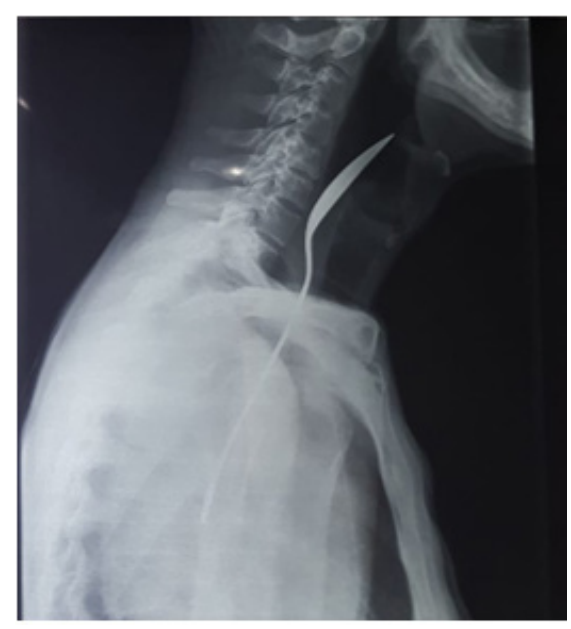

Figure 1: Metallic Spoon on the Cervical X-ray. 


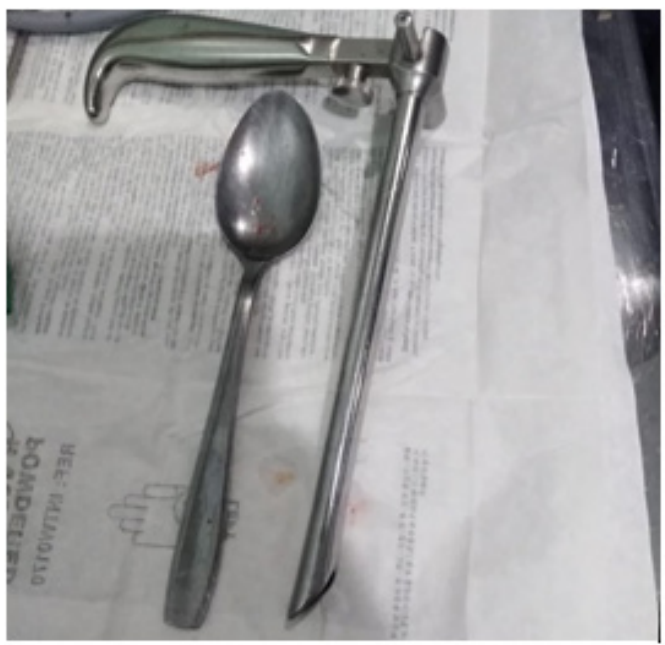

Figure 2: Picture of the Foreign Body After Extraction.

The patient was referred to a psychiatric consultation, according to the nature of the foreign body and the circumstances of occurrence.

\section{Discussion}

Foreign bodies are frequent emergencies in ENT. They can sometimes be life-threatening by their location or their nature. Various factors can be responsible for the aspiration or swallowing of foreign bodies. In adults, the authors affirm that the dental prosthesis is the favoring factor due to the absence of food contact with the lining of the palate [3]. Psychological factors like mental retardation, behavioural disorders, anxiety neurosis and hyperkinetic syndrome also can compound the problem [4]. Foreign bodies in the hypopharynx and esophagus almost always need radiological evaluation to demonstrate the type of the foreign bodies and its location, and the presence of any underlying esophageal conditions [5]. The first diagnostic tool for the evaluation of patients with suspected pharyngo-esophageal foreign bodies is radiography [6]. A large variety of foreign bodies may lodge in the pharynx. In Morocco the most frequent foreign bodies in adults are chicken and meat bones, fish bones, plastic objects and denture [7].

Long objects (greater than $6 \mathrm{~cm}$ ) constitute an emergency in the pharynx and esophagus. They are most often pens, spoons, toothbrushes that you must sometimes know how to turn overusing a polypectomy handle to insert them in a protective tube or protective cap [8]. Foreign bodies cause problems if the site of their impaction is at the narrowest regions such as the glottis and the cricopharyngeal sphincter. Aspirated and ingested foreign bodies can lead to potential complications because of their shape, size and site of impaction. Potential complications include oesophageal perforation, mediastinitis, cervical or mediastinal abscess, emphysema, oesophago-tracheal fistula and septic complications [9]. Raising the awareness of healthcare personnel to refer patients with foreign bodies to ENT emergencies as soon as possible will reduce the rate of complications.

\section{Conclusion}

Foreign pharyngeal bodies of adults are relatively frequent, which must be adequately managed to avoid complications especially if the nature of the foreign body is extremely rare. Extraction under general anesthesia remain the gold standard in the treatment of these localization of foreign body.

\section{Acknowledgement}

None.

\section{Conflict of Interest}

All authors have no conflict of interest or financial support with this article.

\section{References}

1. Latifi H, Alinejad V, Niknejad E (2014) Foreign Body Aspiration-An Experience in Our Community. Hermes Journal France 71(2): 31-39.

2. Bekele A (2014) Aerodigestive Foreign Bodies in Adult Ethiopian Patients: A Prospective Study at Tikur Anbessa Hospital, Ethiopia. Int J otolaryngol.

3. Guelfguat M, Kaplinskiy V, Reddy SH, Di Poce J (2014) Clinical guidelines for imaging and reporting ingested foreign bodies. AJR Am J Roentgenol 203(1): 37-53.

4. Banerjee S (1999) Concept of the foreign body-its past and present. Indian Journal of Otolaryngol Head and Neck Surg 51(Suppl 1): 23-30.

5. Smith MT, Wong RK (2007) Foreign bodies. Gastrointest Endosc Clin N Am 17: 361-382.

6. Pinto A, Muzj C, Gagliardi N, Pinto F, Setola FR, et al. (2012) Role of imaging in the assessment of impacted foreign bodies in the hypopharynx and cervical esophagus. Semin Ultrasound CT MR 33(5): 463-470.

7. Khaoula Hssaine, Btissam Belhoucha (2015) Foreign bodies in ENT: ten-year experience. Pan Afr Med J 21: 91.

8. Lachaux A, Letard JC, Laugier R, Gay G (2007) Recommandations de la société française d'endoscopie digestive, les corps étrangers ingérés. Acta Endoscopica 37(1): 91-93.

9. Wilson RT, Dean PJ, Lewis M (1987) Aortoesophageal fistula due to a foreign body. Gastrointest Endosc 33: 448-450. 